\title{
Calculation of depth to detachment and its significance in the Kuqa Depression: A discussion
}

\author{
Li Shiqin ${ }^{1 *}$, Feng Lei ${ }^{2}$, Tang Pengcheng ${ }^{1}$, Rao Gang ${ }^{1}$ and Bao Yahong ${ }^{3}$ \\ ${ }^{1}$ Department of Earth Sciences, Zhejiang University, Hangzhou, Zhejiang 310027, China \\ ${ }^{2}$ Research Institute of Exploration and Development, Tarim Oilfield Company, PetroChina, Korla, Xinjiang 840000, China \\ ${ }^{3}$ Archives of Tarim Oilfield Company, PetroChina, Korla, Xinjiang 840000, China
}

\begin{abstract}
We analyze the excess area and depth to detachment method developed by Epard and Groshong (1993), and apply it to the sand box model of Ge et al (2004) to illustrate that inadequate consideration will affect the calculation of true depth to detachment. Using the data of Yu et al (2006) to fit linear regression lines, we obtain the depths to detachment of Kela-2, Misikantage anticline and Dongqiu- 8 structures, $115.74 \mathrm{~km}, 14.17 \mathrm{~km}$, and $75.48 \mathrm{~km}$ below the reference level (Cretaceous bottom) respectively with the excess area intercept equal to zero. However, the calculation results of depth to detachment in Yu et al (2006) are based on excess area intercept unequal to zero.
\end{abstract}

Key words: Excess area, depth to detachment, Kuqa Depression

\section{Introduction}

Yu et al (2006) used the excess area method (Epard and Groshong, 1993) to calculate the depth to detachment in the Kuqa Depression, Tarim Basin, China. They took the Kela-2, Misikantage anticline, and Dongqiu- 8 structures as instances to calculate the true depth to detachment with Cretaceous bottom as the reference level. Their result showed that the true detachment level of Kela-2 structure is $5.3 \mathrm{~km}$ below the reference level, that of the Misikantage anticline is $0.25 \mathrm{~km}$ above the reference level, and that of the Dongqiu- 8 structure is $3.2 \mathrm{~km}$ deeper than the reference level (Fig. 5 in Yu et al (2006)).

We agree with Yu et al (2006) in that "use of the excess area diagram makes it possible to predict the detachment level which cannot be discerned in seismic profiles and provides reference information for the interpretation of structural styles and design of balanced cross sections, etc". However, we would like to discuss some drawbacks that arise from their misinterpretation of Fig. 5 in Yu et al (2006).

\section{The Epard and Groshong method}

Epard and Groshong (1993) presented a linear graph method for using the excess area in a fold to determine the depth to detachment. They used the excess areas of multiple horizons to overcome the problems that arise from the Chamberlin method on a single horizon, in which the following five assumptions are typically made (Epard and Groshong, 1993; Chamberlin, 1910).

(1) It is assumed that no material enters or leaves the ends of the cross section. For example, displacement will occur

*Corresponding author. email: shiqinli@yeah.net

Received May 14, 2008 on the upper detachment of a fault bend fold (Suppe, 1983; Fig. 6 in Mitra and Namson, 1989), and layer-parallel shear will also make an originally vertical pin line become tilted or curved (Fig. 10-19 in Mitra and Namson, 1989).

(2) The bed length is assumed to be constant.

(3) The area is assumed to be constant, neither gained (such as by extension fracturing) nor lost (such as by pressure solution).

(4) The original regional elevation of a horizon is assumed to be known, because it may be shifted vertically from its original level by deformation (Homza and Wallace, 1995; 1997; Bulnes and Poblet, 1998; Wallace and Homza, 1998; Wilkerson et al, 2007).

(5) The reference horizon and the lower detachment are assumed to be parallel.

If any one of these assumptions is not satisfied, the excess area calculation is not valid.

Considering these limitations in using the Chamberlin method, Epard and Groshong (1993) developed the excess area method, which uses the excess areas of multiple horizons to overcome the problems that arise from the conventional method for a single horizon. The Epard and Groshong method does not need to measure the bed length, so it eliminates most of the associated assumptions and problems.

We used modified Fig. 1 based on Epard and Groshong (1993) to illustrate the real meaning of this method. There are two variables to be measured: excess area above original level $(S)$ and thickness between reference level and original level (h) (Fig. 1(a) and (c)).

In the case that reference level is the true detachment and constant area is assumed (Fig. 1(a)), the excess area is

$S=D h$

where the slope $(D)$ of the line through the data points represents the displacement of the anticline. At this time, the line goes through the origin (Fig. 1(b)); that is, the line goes 
through the point $S=0, h=0$.

As the reference level is not the true detachment and constant area is also assumed (Fig. 1(c)), the excess area is

$S=D h+S_{\text {a }}$

At this time, the line does not go through the origin, and it intersects the $S$ axis at $\left(0, S_{2}\right)$ (Fig. 1(d)), here,

$$
S_{\mathrm{a}}=D \times h_{\mathrm{e}}
$$

$S_{\mathrm{a}}$ is the shortening area between the true detachment level and the reference level (Fig. 1(c)), $h_{\mathrm{e}}$ is the value of $h$ when the line intersects the $h$ axis at $S=0$, giving the point represents the true detachment (Fig. 1(d)). Therefore, if the line intersects the positive part of the $h$ axis, it means that the true detachment is above the reference level, otherwise the true detachment is below the reference level.

However, transfer of material in the upper detachment deformation system may occur as a consequence of two or more detachments involved in deformation (Ge et al, 2004) (Fig. 2). We know that the core of detachment folds are often ductile rocks, such as evaporites and shales, which can easily migrate laterally (Bulnes and Poblet, 1998; 1999; Homza and Wallace, 1995; 1997; Wallace and Homza, 1998; Wilkerson et al, 2007). Furthermore, subsidence is universal in salt basins. Consequently, using the line intersecting the $h$ axis to determine the true detachment level should be cautious.

In summary, there are some preconditions when using this method: 1) Assuming constant area, we used the ratio of excess area above original level $(S)$ to thickness between reference level and original level $(h)$ to fit a linear regression line and obtained true detachment level (Fig. 1(c) and (d)). 2) When the true detachment level is known, using the line intersecting the $S$ axis at $h=0$ (i.e. $S_{\text {a }}$ ) can illustrate the area moving in or out of the section (Hubert-Ferrari et al, 2007). If the value of $S_{\mathrm{a}}$ is negative, it means $S_{\mathrm{a}}$ area has moved out of the section, but if the value of $S_{\mathrm{a}}$ is positive, it means $S_{\mathrm{a}}$ area has moved in the section. As a result, we cannot use this method without any precondition.

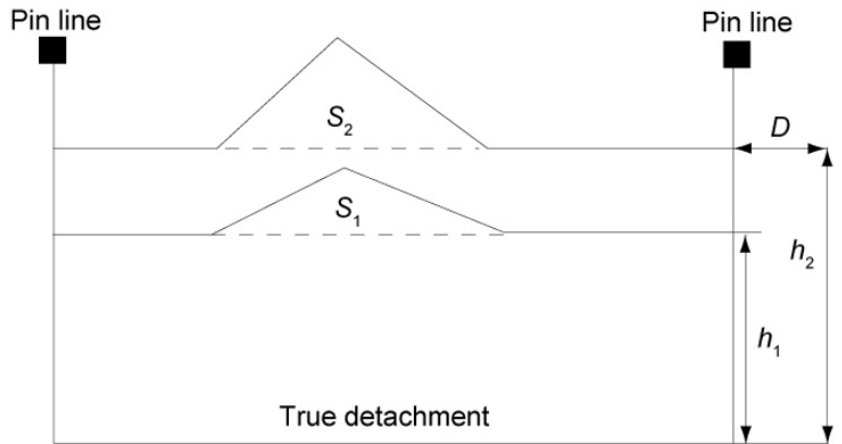

(a)

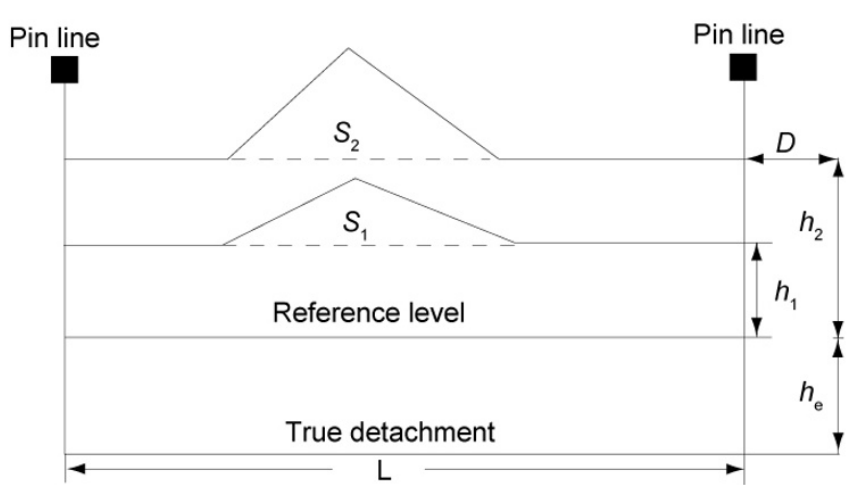

(c)
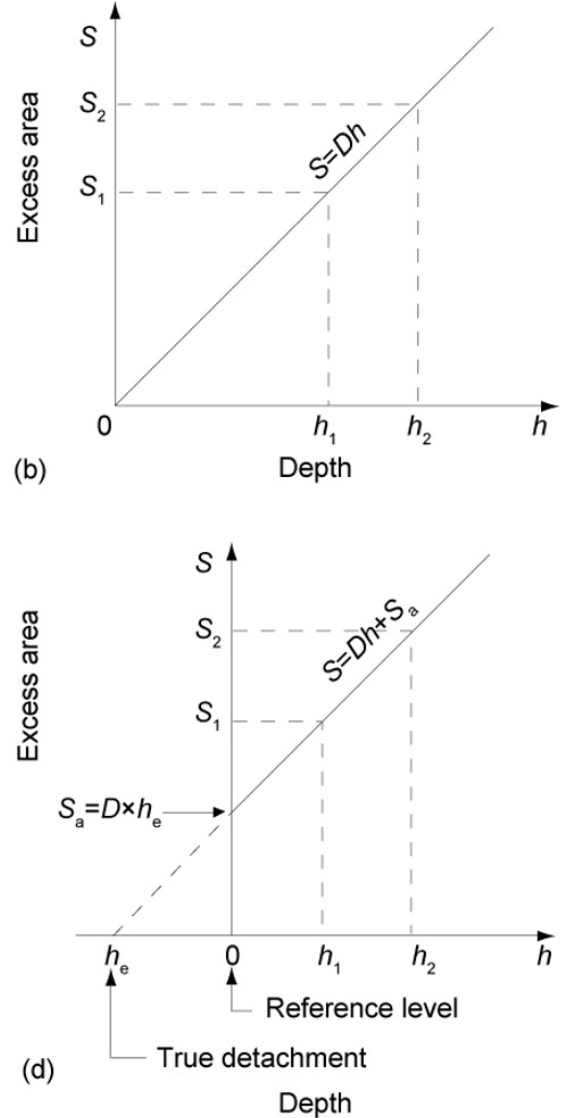

Fig. 1 Excess area balance at two levels of an area-constant anticline

(a) and (c) Cross section of the area-constant anticline; (b) Excess area of section (a); (d) Excess area of section (c) (Epard and Groshong, 1993)

\section{Application to sand box model}

We used a sand box model with two detachments (Fig. 2) (Ge et al, 2004) to illustrate the complicated area balance involved in the Epard and Groshong method (1993).

From the paper of Ge et al (2004), we know that the shortening displacement of the model is $6.3 \mathrm{~cm}$, and it has two detachments involved in deformation. The black layer is salt, the original thickness of which is $0.7 \mathrm{~cm}$, and the layers below and above the salt are sands, the original thickness of which is $3 \mathrm{~cm}$ respectively. We take the salt bottom as the reference level, as well as taking the foreland undeformed level as the original regional level to measure the excess area of the upper detachment system and depth to detachment (Fig. 2, Table 1). Taking the fifth bed for example, its excess area above the original regional level is $A_{1}+A_{3}-A_{2}$, here, $A_{2}$ is probably induced by subsidence. Its depth to detachment is the thickness between the original regional level and salt bottom (i.e. upper detachment level) (Fig. 2). 


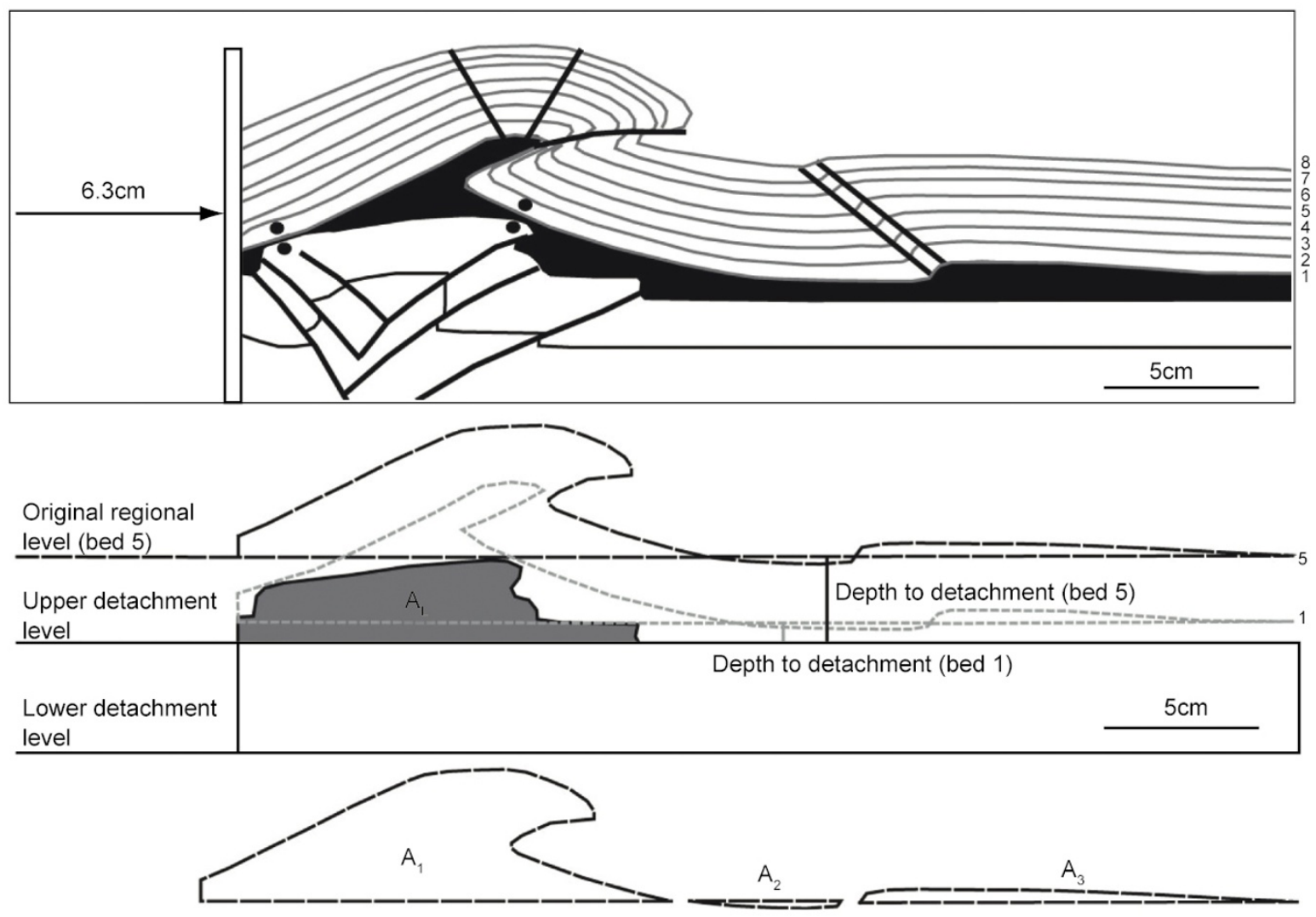

Fig. 2 Redrawn sandbox model from Ge et al (2004)

Table 1 Excess area and depth to detachment measured from section in Fig. 2

\begin{tabular}{ccc}
\hline Bed & Depth to detachment $h, \mathrm{~cm}$ & $\begin{array}{c}\text { Excess area } \\
S, \mathrm{~cm}^{2}\end{array}$ \\
\hline 1 & 1.0 & 27.1 \\
2 & 1.2 & 29.4 \\
3 & 1.8 & 31.0 \\
4 & 2.2 & 33.9 \\
5 & 2.4 & 38.3 \\
6 & 2.7 & 35.4 \\
7 & 3.3 & 38.0 \\
8 & 4.1 & 45.8 \\
\hline
\end{tabular}

Using the excess area method (Epard and Groshong, 1993), we fitted a linear regression line, $S=5.57 h+21.89$, with a correlation coefficient of 0.924 (Fig. 3). Here, $S$ is the excess area $\left(\mathrm{cm}^{2}\right), h$ is the thickness between salt bottom (reference level) and original regional level of horizon (cm). The slope of the line is 5.57 which means that the displacement of the upper detachment is $5.57 \mathrm{~cm}$, which is slightly less than the real shortening displacement $(6.3 \mathrm{~cm})$. Moreover, the line intersects the $S$ axis at $h=0$ and the intercept is 21.89 (i.e. $S_{\mathrm{a}}=21.89 \mathrm{~cm}^{2}$ ). As we know that the salt bottom is the real detachment level of the upper deformation system, $S_{\mathrm{a}}=21.89 \mathrm{~cm}^{2}$ means that there are $21.89 \mathrm{~cm}^{2}$ excess area moving in the upper deformation system. By measuring, we know that the involved excess area of lower detachment is $\mathrm{A}_{\mathrm{L}}=21.19 \mathrm{~cm}^{2}$ above the salt bottom, which is nearly equal to the line intercept of the $S$ axis (i.e. $S_{\mathrm{a}}$ ) at $h=0$. It means that most of the excess area moving in the upper detachment system comes from the lower detachment deformation system. We think the difference between the model and our data may come from measurement and drawing inaccuracies, and lateral transfer of salt is probably another factor.

However, if we do not consider the lower detachment area involved in deformation (Fig. 2), we will get depth intercept $h_{\mathrm{e}}=-3.93 \mathrm{~cm}$, so an improper conclusion that the true detachment level is $3.93 \mathrm{~cm}$ below the reference level (salt bottom) will be drawn (Fig. 3).

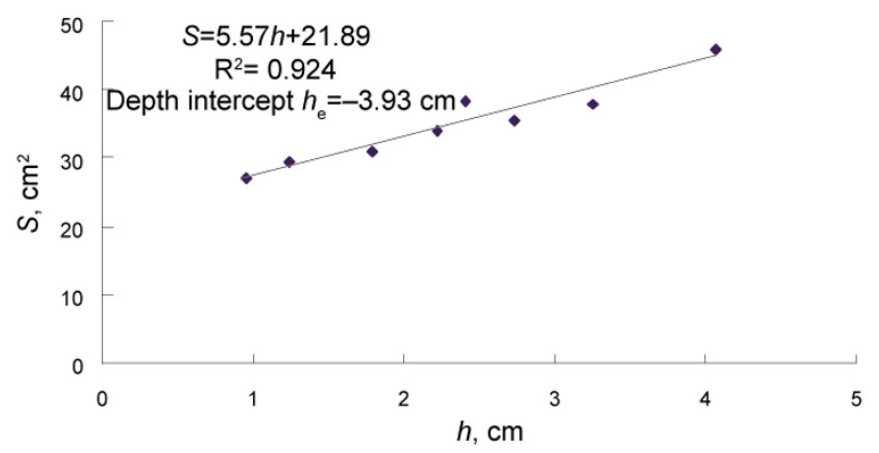

Fig. 3 Illustration of excess area in Fig. 2 


\section{Application to Yu et al (2006) example}

We used the data in Table 1 of Yu et al (2006) to fit linear regression lines (Fig. 4).

The equation for Kela- 2 is $S=0.1452 h+16.806$, with a correlation coefficient of 0.3733 (Fig. 4(a)). Firstly, the correlation coefficient of these data is not satisfactory. Secondly, the line intersects the $h$ axis at $S=0, h_{\mathrm{e}}=$ $-115.74 \mathrm{~km}$. Therefore, if without regard to other factors such as step fault, the true detachment level should be $115.74 \mathrm{~km}$ below the reference level (Cretaceous bottom), which is impossible in Kela-2 area. Whereas, the $5.3 \mathrm{~km}$ below the reference level of Yu et al (2006) is based on the line intersecting the $h$ axis at $S^{\prime}=16 \mathrm{~km}^{2}$; that is, $h_{\mathrm{e}}{ }^{\prime}=$ $(16-16.806) / 0.1452=-5.3 \mathrm{~km}$.

Analogously, the equation for the Misikantage anticline is $S=1.0392 h+14.735$, with a correlation coefficient of 0.9838 (Fig. 4(b)). As a result, the true detachment should be $14.17 \mathrm{~km}$ below the reference level if without regard to other factors such as lateral movement of salt, while the $0.25 \mathrm{~km}$ above the reference level of Yu et al (2006) is based on the line intersecting the $h$ axis at $S=15 \mathrm{~km}^{2}$.

The equation for the Dongqiu- 8 structure anticline is $S=0.1714 h+12.938$, with a correlation coefficient of 0.9772 (Fig. 4(c)). As a result, the true detachment is $75.48 \mathrm{~km}$ below the reference level if without regard to other factors, whereas the $3.2 \mathrm{~km}$ below the reference level of Yu et al (2006) is based on the line intersecting the $h$ axis at $S^{\prime}=12.5 \mathrm{~km}^{2}$.

In conclusion, we think $\mathrm{Yu}$ et al (2006) may have misinterpreted the real meaning of their Fig. 5.
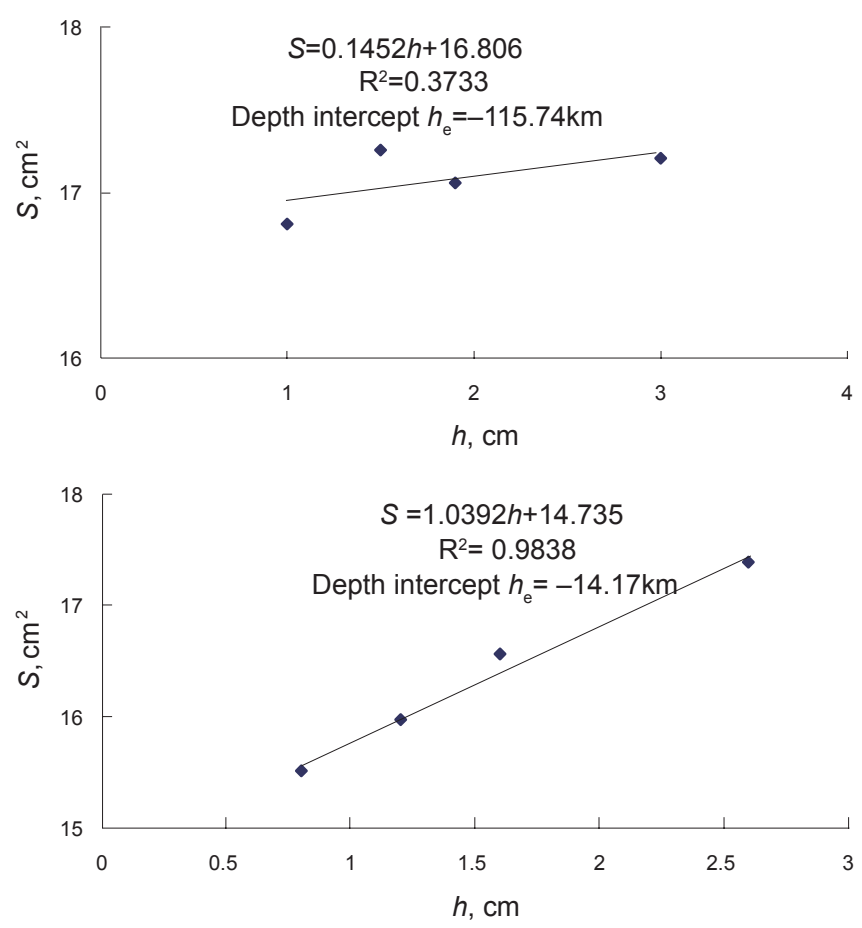

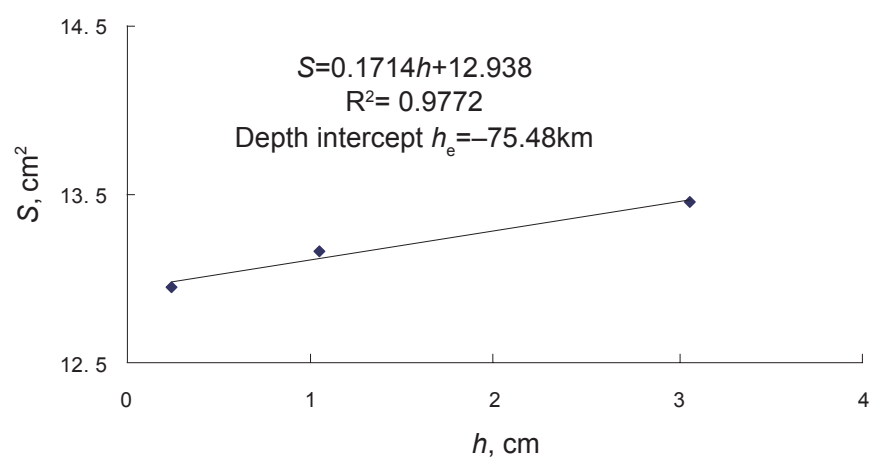

Fig. 4 Redrawn excess area of Fig. 5 in Yu et al (2006)

(a) Kela-2; (b) Misikantage anticline; (c) Dongqiu-8 structure

\section{References}

Bulnes M and Poblet J. Detachment folds with fixed hinges and variable detachment depth, northeastern Brooks Range, Alaska: Discussion. Journal of Structural Geology. 1998. 20(11): 1587-1590

Bulnes $\mathrm{M}$ and Poblet J. Estimating the detachment depth in cross sections involving detachment folds. Geological Magazine. 1999. 136(4): 395-412

Chamberlin R T. The Appalachian folds of central Pennsylvania. Journal of Geology. 1910. 27: 228-251

Epard J L and Groshong R H. Excess area and depth to detachment. AAPG Bulletin. 1993. 77(8): 1291-1302

Ge H X, Vendeville B C and Jackson M P A. Physical models of thickskinned contractional salt tectonics in a foreland fold-and-thrust belt. Geological Journal of China Universities. 2004. 10(1): 39-49 (in Chinese)

Homza T X and Wallace W K. Geometric and kinematic models for detachment folds with fixed and variable detachment depths. Journal of Structural Geology. 1995. 17(4): 575-588

Homza T X and Wallace W K. Detachment folds with fixed hinges and variable detachment depths, northeastern Brooks Range, Alaska. Journal of Structural Geology. 1997. 19(3-4): 337-354

Hubert-Ferrari A, Suppe J, Gonzalez-Mieres R, et al. Mechanisms of active folding of the landscape (southern Tian Shan, China). Journal of Geophysical Research. 2007. 112, B03S09

Mitra S and Namson J S. Equal-area balancing. American Journal of Science. 1989. 289: 563-599

Suppe J. Geometry and kinematics of fault-bend folding. American Journal of Science. 1983. 283: 684-721

Wallace W K and Homza T X. Detachment folds with fixed hinges and variable detachment depths, northeastern Brooks Range, Alaska: Reply. Journal of Structural Geology. 1998. 20(11): 1591-1595

Wilkerson M S, Smaltz S M, Bowman D R, et al. 2-D and 3-D modeling of detachment folds with hinterland inflation: A natural example from the Monterrey Salient, northeastern Mexico. Journal of Structural Geology. 2007. 29(1): 73-85

Yu Y X, Tang L J, Yin J Y, et al. Calculation of depth to detachment and its significance in the Kuqa Depression. Petroleum Science. 2006. 3(2): $34-38$

(Edited by Hao Jie) 